\title{
Carbon Footprints, life cycle analysis, food miles - global trade trends and market issues
}

\section{Caroline Saunders}

\section{Introduction}

Historically trade policy has been one of the major factors affecting NZ exports. This is still important with NZ restricted by quotas especially for access into high value markets. Moreover, other potential markets for NZ have been affected by the competition from subsidised exports. The EU (European Union) has recently announced it is going to, even without the completion of current Doha round of the WTO (World Trade Organisation), remove export subsidies. This has huge potential for our products.

However, a great threat to our access especially into the high value markets is the growing concern about the environment. In particular the issue of climate change has grown in importance as seen through the application of the Kyoto Protocol and issues such as "food miles". This paper outlines some of these threats. Whilst this concentrates upon the UK and EU markets there is growing evidence that this is not just an issue for those markets. Other markets are also showing increasing concern about these factors.

\section{Food Miles}

'Food miles' is a relatively recent issue which has arisen in the United Kingdom, Germany and other countries over food transportation. A simple definition of this concept would be: 'the number of miles (kilometres) a product has to be transported from the farmer/grower to various stages of production until it reaches the supermarket and finally the plate of the consumer'. It has been born out of concern for the environment, especially in regard to greenhouse gas emissions such as carbon dioxide and the global warming arising from this. The argument is that the longer the transport distance (food miles), the more energy is consumed, the more fossil fuels are burned and consequently the more greenhouse gases are released into the air, which cause climate change. Therefore the solution proposed by food miles campaigners is to source food from as close to where it will be finally consumed as possible.

New Zealand has attracted a lot of attention in the food miles debate for three main reasons. Firstly, due to its geographical location relative to the EU, New Zealand products imported by the EU have to travel a very long distance, making the apparent food miles high. The second reason is that the EU, especially the UK, have traditionally been important high 
value markets for $\mathrm{NZ}$ exports. Third, the similar climates of $\mathrm{NZ}$ and, in particular the UK, mean that the land is suitable for similar farming activities. This leads to the argument that the EU can substitute a significant proportion of what New Zealand exports to their country to a lesser or greater extent with home-grown produce.

In the Food Miles Report produced by the AERU key New Zealand sectors were evaluated concentrating upon those which export significant quantities to the $\mathrm{UK}$, and compared to the next best alternative source for the UK market. The calculation of energy use was based upon a life cycle assessment-type approach. However it just covers the environmental impact categories of energy use and $\mathrm{CO}_{2}$ emissions and from production to UK port. The analysis first identified the farm production system in New Zealand and the UK or where there wasn't an equivalent UK system the relevant EU country which could be used as an alternative source of supply to the UK market. The key features of the study was that it used the same methodology when comparing NZ to the UK and its transparent methodology (Saunders, Barber et al. 2006).

The report found that the UK uses twice as much energy per tonne of milk solids than NZ, even including the energy associated with transport from NZ to the UK. This reflects the less intensive lower input production system in NZ compared to the UK. The energy used in producing lamb in the UK is four times higher than the energy used by NZ lamb producers,

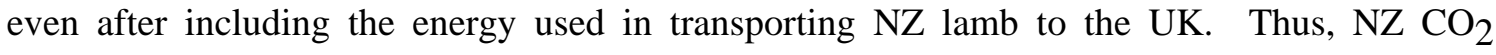
emissions are also considerably lower than those in the UK. NZ is also more energy efficient in producing and delivering apples to the UK market than the UK is. NZ energy costs for production are a third of those in the UK. Even when transport is added NZ energy costs are approximately 60 per cent of those in the UK. Consequentially the $\mathrm{CO}_{2}$ emissions per tonne of apples produced are also higher in the UK than in NZ, reflecting the higher energy use but also the lower emissions from NZ electricity generation. The energy associated with onion production is higher in NZ compared with the UK. However, when storage is included for the UK, so they can supply the same market window as NZ can, the UK energy costs rise to 30 per cent higher than those in NZ, even accounting for transport.

A number of caveats should be noted when interpreting these results. The most important of these was the lack of comparable data between the countries and more importantly the lack of data in particular for the EU countries on production systems and their energy use. A second important caveat is that the analysis assumes that the EU would be able to meet the shortage of supply if NZ did not supply the EU market. It also assumes that this can be done using the same levels of inputs currently used which may not be the case. To supply these would mean that land would have to be diverted from other uses and this land is unlikely to be of the same quality as existing land producing the product and therefore may well require greater inputs. 
However, food miles has become a well understood and accepted concept by UK consumers and may affect the type of food they buy. For example, the consumption of potatoes grown by local producers is on the rise in the UK and outranks the consumption of dry pasta and rice. In addition, one should not undermine the possibility of future restrictions from importing countries, via regulatory means or more likely via market pressure (retailers or consumers).

The issue of food miles is still active and there is still considerable interest in the original report from around the world. As the NZTE sponsored research has shown the awareness of food miles has risen from 2006 from 39 per cent to 59 per cent in 2007 a bit concerning as this was the period in which the Food Miles report was most highly profiled. However, in a suite of concerns affecting consumers food miles was rated the lowest at 22 per cent compared to 68 per cent for recycling, 53 per cent for climate change and 48 per cent for child labour (Promar Digest 2008). The food miles debate has highlighted the importance of the issue of climate change in consumers and politicians minds and the growing importance of reducing carbon emissions. Hence the movement towards carbon footprinting of individuals, supply chains and products.

\section{Carbon Footrpinting}

This is an issue which is continuing to grow in importance. In the UK there is political consensus over this issue, moreover the UK has taken the lead in this area in the EU with the Climate Change Bill aiming to reduce emissions by 60 per cent from 1990 to 2050, (13 per cent of UK emissions come from food). The UK has been able to take this lead due to change over from coal to gas fired power stations. In the UK the Committee on Climate Change will be established, this is an independent, statutory body to advise on how carbon emission can be reduced. Its first task will be to set three five year 'carbon budgets' for the period 2008 to 2022. In doing so it has to consider scientific, economic and social factors.

The EU is following this lead, as is NZ with John Key proposing a 50 per cent reduction in emissions from NZ over a similar time frame. Other countries are also following suit even countries such as the US which are not part of Kyoto agreement. Japan also has announced a 50 per cent reduction in emissions by 2050 .

In the UK recent surveys have found that 94 per cent of respondents are concerned about climate change with 66 per cent actually taking personal action to reduce their carbon footprint. The UK has taken the lead in carbon labelling and carbon ratings. For example, The Carbon Trust, an independent body whose aim is to help companies to reduce their carbon emissions, has launching a trial carbon labelling scheme. Products have labels stating the carbon dioxide emitted during the full life-cycle of an item. The scheme also requires the firm producing the product to commit to reducing their the carbon footprint 
Tesco have stated that all products in its store will receive a carbon rating and are investing $£ 500$ million pounds to do this. Marks and Spencer are investing $£ 200$ million to reduce its carbon footprint by 80 percent over five years. Both Marks and Spencer and Tesco have airplane symbols on all food products freighted to the UK (Hickman 2007).

Currently the Carbon Trust, DEFRA and British Standard Institute are developing a draft Publicly Available Specification (PAS) 2050 to assess life-cycle greenhouse gas emissions of products and services. It is predicted that this will set the standard for carbon labelling internationally although the current draft has seen some decline in this prediction. The draft PAS is now being trialled on 75 product ranges and 20 UK food industry organisations such as Cadbury Schweppes, Coca-Cola, Dairy UK Ltd and British Sugar.

\section{Other factors affecting our trade}

A number of other issues have arisen from the general concern about the environment and climate change. One of these is the risk to general consumption of meat and dairy products which generally have a high carbon footprint (mainly through methane and nitrous oxide emissions) and so it is argued that their consumption should be reduced. This can be seen in the growth of individual carbon footprinting which highlights the higher carbon footprint if eating meat.

Other issues which have arisen are the rise in the debate about seasonal consumption and the debate of consuming locally produced foods. Studies in the US show that locally grown food labels play a great influence on consumers. Given a choice, consumers are more likely to purchase locally grown over organic foods produced in a distant region, even if the local foods were produced using some pesticides. This is given impetus by the rise in popularity of local food markets.

Clearly, it is important for New Zealand agri-businesses to show they are 'carbon-friendly' and reducing their footprint. Interestingly it was the reduction which is being stressed rather than offsetting. Offsetting had lost some credibility in the UK firstly because it was seen as dodging the problem but also some schemes had been shown to be spurious and verging on fraudulent.

Another very important factor potentially to affect the issue of carbon footprinting and other environmental and social aspects of food production which may affect our market access is the interdiction of the Single Farm Payment in the EU. This is a huge change in policy from market based support (which has historically and still causes NZ hardship) to direct payments to farmers based on environmental criteria. The budget for this is huge with 75 billion Euros per year almost equivalent to NZ's national income. 
The CAP 2003 reform includes a Single Farm Payment (SFP) in which subsidies are decoupled from production. That is farmers receive a payment irrespective of what and how much they choose to produce. The EU commission has recently announced that climate change issues will be included as part of these payments. This potentially means that individual farms in the EU will measure their carbon footprint and access to the payment will depend upon reducing this footprint. Consequently this may well mean we have to do the same in NZ and individually carbon footprint all farms. Whilst this may seem a huge undertaking it does have the advantage that farmers here are generally better place to do his than many of our competitors and moreover farmers generally find financial savings when these audits are undertaken (Agra Europe 2007).

The CAP reform of 2003 also brings the importance of environment, quality and safety issues into the EU agricultural support. To benefit from the SFP, farmers will have to comply with existing legislation on those issues (cross-compliance). Assistance in the form of advisory services for farmers is foreseen to help EU farmers to meet the standards. In addition the support for voluntary agri-environmental measures has increased. Incentives are foreseen for farmers who join food quality certification schemes and consumer information campaigns (EU 2003).

The introduction of the SFP and also the agri-environmental schemes in the EU has lead to greater emphasis on other environmental factors including biodiversity, water quality and wildlife. The payments will help to subsidise farmers to meet requirements for these on their farms and the market requirements may well increase for these attributes. This can already be seen in the growth of such schemes as EureGAP which include requirements or recommendations for environment and hygiene, environmental management including wildlife policy, groundwater, staff facilities, training and health and safety. Whilst not all of these are "must dos" at present the subsidisation of EU farmers to meet these requirements will enable them to become "must dos" sooner.

\section{Conclusion}

In conclusion NZ exporters have growing opportunities in the world market as export subsidies are reduced and removed. However, this opportunity may well rely on production meeting various environmental criteria especially to access high-value markets. Climate change is the most recent example of these criteria from which issues such as food miles have arisen. This is clearly an erroneous concept as it ignores the full energy and carbon emissions from production as the Lincoln AERU Food Miles report showed. Food miles, whist still having traction with the popular media and maybe consumers, has lost credibility with the supermarkets and government agencies who have turned their attention to carbon footprinting. The emphasis now is therefore 
on measuring the carbon footprint of products and currently DEFRA, the Carbon Trust and BSI are developing a method to do this. The key in factor is reducing carbon footprint over time.

\section{References}

Agra Europe (2006) 2233.

Agra Europe (2007) various issues

Agra Facts (2006). 87(6).

Christensen, V. and C. Saunders (2003). Economic Analysis of Issues Concerning Organic Dairy Farming. Christchurch, AERU, Lincoln University.

EU (2003). Council regulation (EC) N0 1782/2003 of 29 September 2003.

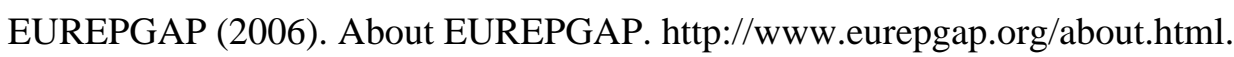

Fisher Boel, M. (2006). Member of the European Commission responsible for Agriculture and

Rural Development: Reform of the Fruits and Vegetables CMO: Speech to European Parliament Inter-group on fruit and vegetables. Strasbourg.

Leopold Center for Sustainable Agriculture (2004). Ecolabel Value Assessment Phase II: Consumer Perceptions of Local Foods, Iowa State University.

Martech Consulting Group (n.d). Trends that impact New Zealand's horticultural food exports. Trends in Horticultural Foods.

OECD (2003). Agri-Environmental policy measures: overview of developments, Organisation for Economic Co-operation and Development.

Saunders, C., A. Barber, et al. (2006). Food Miles - Comparative Energy/Emissions Performance of New Zealand's Agriculture Industry, AERU - Lincoln University.

Wilkins, J. (2006). SNE 2005 Kicks Off With a Look at Food Systems and Health. Division of Sustainable Food Systems Newsletter. Society for Nutrition Education. wwww.sne.org/sne2005 conferencematerials.htm 